\title{
Supplemental UV-A and UV-B Affect the Nutritional Quality of Lettuce and Tomato: Health-Promoting Phytochemicals and Essential Nutrients
}

\author{
Myungjin Lee1 ${ }^{1}$, Cary Rivard ${ }^{2}$, Eleni Pliakoni³, Weiqun Wang', C. B. Rajashekar ${ }^{1 *}$ \\ ${ }^{1}$ Department of Horticulture and Natural Resources, Kansas State University, Manhattan, KS, USA \\ ${ }^{2} \mathrm{~K}$-State Olathe Horticulture Research and Extension Center, Olathe, KS, USA \\ ${ }^{3}$ Department of Horticulture and Natural Resources, Kansas State University, Olathe, KS, USA \\ ${ }^{4}$ Department of Food, Nutrition, Dietetics and Health, Kansas State University, Manhattan, KS, USA \\ Email: *crajashe@ksu.edu
}

How to cite this paper: Lee, M., Rivard, C., Pliakoni, E., Wang, W.Q. and Rajashekar, C.B. (2021) Supplemental UV-A and UV-B Affect the Nutritional Quality of Lettuce and Tomato: Health-Promoting Phytochemicals and Essential Nutrients. American Journal of Plant Sciences, 12, 104-126.

https://doi.org/10.4236/ajps.2021.121007

Received: December 3, 2020

Accepted: January 25, 2021

Published: January 28, 2021

Copyright $\odot 2021$ by author(s) and Scientific Research Publishing Inc. This work is licensed under the Creative Commons Attribution International License (CC BY 4.0).

http://creativecommons.org/licenses/by/4.0/

(c) (i) Open Access

\begin{abstract}
UV radiation plays an important role not only in plant growth and development but also in the accumulation of essential nutrients and health-promoting phytochemicals in plants. The main objective of this study was to examine the effects of supplemental UV-A, UV-B, and UV-AB on the nutritional quality of lettuce (Lactuca sativa, cv. red leaf "New Red Fire" and green leaf "Two Star") and tomato (Solanum lycopersicum L., cv. BHN-589) grown in a greenhouse. Supplemental UV radiation was provided by UV lamps 5 - 6 days prior to harvest. Supplemental UV-A produced higher accumulation of total phenolic compounds and higher antioxidant capacity in red leaf lettuce compared to other treatments. Overall, supplemental UV-A produced a stronger response than other UV treatments and control in the accumulation of many phenolic compounds including luteolin-7-glucoside, quecetin-3-glucoside, and apigenin-3-glucoside in red leaf lettuce. However, UV-B and UV-AB had a negative response in the accumulation of many phenolic compounds including chlorogenic acid, luteolin-7-glucoside, quercetin-3-glucoside, and apigenin-3-glucoside in both red and green leaf lettuce varieties. In tomato fruits, supplemental UV-A had no effect on their total phenolic concentration. However, supplemental UV-B radiation for $3 \mathrm{~h}$ or UV-AB radiation for $9 \mathrm{~h}$ exposure produced higher total phenolic concentration in the fruits compared to other supplemental UV treatments. Supplemental UV-AB (3 hexposure) was generally more effective than other UV treatments in increasing the accumulation of a number of phenolic compounds including chlorogenic acid, caffeic acid, chicoric acid, luteolin-7-glucoside, and other
\end{abstract}


flavonoids in ripe tomato fruits. Supplemental UV-A produced higher accumulation of carotenoids including lutein and $\beta$-carotene than other supplemental UV treatments, while supplemental UV-AB increased the accumulation of lycopene in fully ripe tomatoes. With regard to the essential nutrients, green leaf lettuce was more responsive to the supplemental UV treatments than red leaf lettuce. All the supplemental UV treatments produced an increase in protein concentration in the leaves of green leaf lettuce. However, supplemental UV-AB produced a stronger response compared to the control and other UV treatments in increasing the accumulation of many nutrients including protein, phosphorus, potassium, sulfur, and zinc in green leaf lettuce "Two Star". Supplemental UV-treatments did not affect the accumulation of any essential nutrients in fully ripe tomato fruits. The results show that supplemental UV enhances the nutritional quality of lettuce in relation to both health-promoting phytochemicals and essential nutrients. Similarly, supplemental UV enhances nutritional quality in tomato fruits with higher accumulation of both phenolic compounds and carotenoids than does the control treatment.

\section{Keywords}

Greenhouse, Lettuce, Micronutrients, Nutritional Quality, Phytochemicals, Spectral Quality, Tomato, UV-A and UV-B

\section{Introduction}

UV radiation (UV-A and UV-B) plays an important role in the growth and development of plants [1] [2]. Of the total solar UV radiation reaching plants, the major part is UV-A radiation (315 - $400 \mathrm{~nm}$ ), while the shorter wavelength UV-B (280 - $315 \mathrm{~nm}$ ), which comprises only 5\%, is more energetic and has been studied extensively with regard to its role in various plant functions including growth, morphogenesis, plant adaptation, and physiological processes such as photosynthesis and secondary metabolism [3] [4] [5]. Impact of UV radiation on various aspects of vegetative and reproductive growth and the accumulation of secondary metabolites, including phenolic compounds and carotenoids in several crop species, has been reviewed by Huche-Thelier et al. [6]. On the one hand, UV-radiation, especially UV-B, can induce reactive oxygen species, which can be damaging to many organelles and macromolecules and impair photosynthetic function leading to reduced growth [7] [8]. On the other hand, it can also trigger the production of antioxidant species, which have a defensive function in plants [9]. UV radiation can induce a plethora of phenolic compounds, especially flavonoids which not only protect plants against high doses of UV-B but as they are antioxidants they also have health-promoting qualities. They are known to reduce the risk of many common chronic and degenerative diseases including cardiovascular diseases, cancers, diabetes, and arthritis; more importantly they promote overall health in humans [10] [11]. Therefore, it is important to devel- 
op strategies to improve the nutritional quality of our food in relation to health-promoting phytochemicals and essential nutrients. The role of UV radiation in activating secondary metabolism has been reported in a number of plant species including lettuce [5]. Crops grown in open fields with the benefit of solar radiation consisting of UV radiation have been shown to have increased health-promoting phytochemicals [12] [13]. Thus, UV radiation can have an impact on health-promoting phytochemicals. However, it is not clear whether it also has any effect on the accumulation of essential nutrients in plants, which can have major impacts on the overall nutritional quality of our food [10].

Malnutrition is a major global public health challenge arising from inadequate consumption of both macronutrients (calorie rich foods and proteins) and many micronutrients [14]. Although it is a more serious problem in developing countries, it is prevalent in most regions of the world including the U.S. [15]. The nutrients of major concern are protein (globally a billion people have chronic inadequate protein consumption) [16] and many micronutrients including calcium, iron, zinc, and many others [17] [18]. Efforts to mitigate the challenges of malnutrition have included primarily the consumption of nutrient-rich food and using supplements [14] [18]. Improving nutritional quality by developing nutrient-dense food is a critical challenge in addressing the issue of nutrient deficiency and malnutrition. Therefore, in this study, we investigated the effects of supplemental UV-A, UV-B, and UV-AB on the growth and the nutritional quality of common vegetables, namely lettuce and tomato, in relation to their health-promoting phytochemicals and essential nutrients.

\section{Materials and Methods}

\subsection{Plant Growing Conditions}

Seeds of two varieties of lettuce (Lactuca sativa), a red leaf, "New Red Fire" and a green leaf, “Two Star” were sown in 72-cell plug trays containing Metromix 360 soil mix, (Sungro Horticulture, Agawam, MA) in a growth chamber set at $22^{\circ} \mathrm{C}$ (day/night) with a PAR photon flux of $274 \mu \mathrm{mol} / \mathrm{m}^{2} / \mathrm{s}$, a $12 \mathrm{~h}$ photoperiod and $60 \%$ relative humidity $(\mathrm{RH})$ on May $5^{\text {th }}, 2017$. One week old seedlings were then transplanted into pots $(12 \mathrm{~cm} \times 12 \mathrm{~cm} \times 12 \mathrm{~cm})$ containing Metro 360 soil mix, and after 3 weeks, seedlings were then transferred to a greenhouse maintained at $25^{\circ} \mathrm{C}$ and $70 \% \mathrm{RH}$ with an average solar PAR flux of $719 \mu \mathrm{mol} / \mathrm{m}^{2} / \mathrm{s}$. The studies were conducted at the greenhouse facilities at Kansas State University, Manhattan, KS. Plants were irrigated 4 times a week and fertilized once a week with fertilized water (N:P:K-20-10-20) at 200 ppm of nitrogen. The total UV solar radiation in the greenhouse was measured using a Research Radiometer (ILT 5000, International Light Technologies, Inc., Peabody, MA) during mid-day at the canopy level. Plants were treated with supplemental UV just after sunset prior to harvest using UV lamps (UV-A 340 and UV-B 313EL, Q-Lab Corp., Cleveland, $\mathrm{OH})$. Plants were treated with UV-A $\left(8.11 \mathrm{~W} / \mathrm{m}^{2}\right)$, UV-B $\left(1.97 \mathrm{~W} / \mathrm{m}^{2}\right)$ and $\mathrm{UV}-\mathrm{AB}\left(5.08+1.55 \mathrm{~W} / \mathrm{m}^{2}\right)$ for 5 or 6 days prior to harvest as indicated in Table 
1. UV exposure treatments were started on June $2^{\text {nd }}, 2017$. The experiment was laid out in a randomized complete block design (RCBD) with 3 replications.

Tomato seeds [Solanum lycopersicum L. (cultivar "BHN-589")] were germinated in 32 cells plug trays containing Metro-mix 360 on July $7^{\text {th }}$, 2017. The plants were grown in a growth chamber set at $25^{\circ} \mathrm{C} \pm 2{ }^{\circ} \mathrm{C}$ and $60 \%$ relative humidity and with a $16 \mathrm{~h}$ photoperiod and a PAR photon flux of $288 \mu \mathrm{mol} / \mathrm{m}^{2} / \mathrm{s}$ for 4 weeks. The plants were then transferred to pots $\left(21.5^{\prime \prime}\right.$ diameter $\times 21$ " height) with the same soil mix as above (Aug $8^{\text {th }}, 2017$ ). Transplanted seedlings were moved to a greenhouse maintained at $25^{\circ} \mathrm{C}$ and $70 \%$ relative humidity and were grown for 60 days before the supplemental UV treatments (October $4^{\text {th }}, 2017$ ). The plants were irrigated to field capacity 3 times a week and fertilized once a week with fertilized water as described above. The average solar light intensity and the supplemental UV treatments were same as outlined for lettuce plants. UV-B and UV-AB (UV-A + UV-B) treatments each consisted of 3 exposure periods, namely $3 \mathrm{~h}, 6 \mathrm{~h}$ and $9 \mathrm{~h}$ with $1.5 \mathrm{~h}$ exposure/day, 6 days before harvest (Table 1). UV exposure treatments were started on October $5^{\text {th }}, 2017$. The experiment was conducted using an RCBD layout with 3 replications. Fruits were harvested after the UV treatments and were sorted into breaker and ripe stages, which were separately analyzed for various characteristics.

Table 1. Supplemental UV radiation treatment schedule for lettuce and tomato plants grown in greenhouse. The daily treatments were initiated after the sunset just prior to harvest. UV exposure started on June $2^{\text {nd }}, 2017$ for lettuce and on October $5^{\text {th }}, 2017$ for tomato.

\begin{tabular}{|c|c|c|c|c|c|c|c|}
\hline & \multirow{2}{*}{$\begin{array}{l}\text { Supplemental } \\
\text { radiation }\end{array}$} & \multicolumn{5}{|c|}{ Treatment schedule } & \\
\hline & & Day 1 & Day 2 & Day 3 & Day 4 & Day 5 & \\
\hline \multirow{5}{*}{ Lettuce } & Control & - & - & - & - & - & \\
\hline & UV-A & $24 \mathrm{~h}$ & $24 \mathrm{~h}$ & $24 \mathrm{~h}$ & $24 \mathrm{~h}$ & $24 \mathrm{~h}$ & \\
\hline & UV-B & - & $2 \mathrm{~h}$ & $2 \mathrm{~h}$ & $2 \mathrm{~h}$ & $2 \mathrm{~h}$ & \\
\hline & UV-AB & - & $2 \mathrm{~h}$ & $2 \mathrm{~h}$ & $4 \mathrm{~h}$ & $4 \mathrm{~h}$ & \\
\hline & & Day 1 & Day 2 & Day 3 & Day 4 & Day 5 & Day 6 \\
\hline \multirow{8}{*}{ Tomato } & Control & - & - & - & - & - & - \\
\hline & UV-A & $24 \mathrm{~h}$ & $24 \mathrm{~h}$ & $24 \mathrm{~h}$ & $24 \mathrm{~h}$ & $24 \mathrm{~h}$ & $24 \mathrm{~h}$ \\
\hline & UV-B $3 \mathrm{~h}$ & $1.5 \mathrm{~h}$ & $1.5 \mathrm{~h}$ & & & & \\
\hline & UV-B $6 \mathrm{~h}$ & $1.5 \mathrm{~h}$ & $1.5 \mathrm{~h}$ & $1.5 \mathrm{~h}$ & $1.5 \mathrm{~h}$ & & \\
\hline & UV-B $9 \mathrm{~h}$ & $1.5 \mathrm{~h}$ & $1.5 \mathrm{~h}$ & $1.5 \mathrm{~h}$ & $1.5 \mathrm{~h}$ & $1.5 \mathrm{~h}$ & $1.5 \mathrm{~h}$ \\
\hline & UV-AB $3 \mathrm{~h}$ & $1.5 \mathrm{~h}$ & $1.5 \mathrm{~h}$ & & & & \\
\hline & UV-AB $6 \mathrm{~h}$ & $1.5 \mathrm{~h}$ & $1.5 \mathrm{~h}$ & $1.5 \mathrm{~h}$ & $1.5 \mathrm{~h}$ & & \\
\hline & UV-AB $9 \mathrm{~h}$ & $1.5 \mathrm{~h}$ & $1.5 \mathrm{~h}$ & $1.5 \mathrm{~h}$ & $1.5 \mathrm{~h}$ & $1.5 \mathrm{~h}$ & $1.5 \mathrm{~h}$ \\
\hline
\end{tabular}




\subsection{Growth Characteristics}

All the growth characteristics were measured at the time of harvest. The fresh weights of shoots and roots of lettuce were measured, and their dry weights were obtained after freeze-drying (Harvest Right, North Salt Lake, Utah) until a constant sample weight was reached. Leaf area was measured using an LI-3100 Area Meter (LI-COR, Inc., Lincoln, Nebraska). Specific leaf weight was calculated by dividing dry leaf weight by leaf area. Tomato fruits were harvested beginning in early October, 2017. Samples of lettuce leaves and tomato fruits (pericarp) were freeze-dried and stored at $-20^{\circ} \mathrm{C}$ for further analyses. All chemical analyses involved measurements on 4 replicates.

\subsection{Chlorophyll and Carotenoids}

The chlorophyll and carotenoid concentrations in lettuce leaves were determined according to the methods by Pora et al. [19] and Chen et al. [20] with some modifications. Lettuce leaf $(0.03 \mathrm{~g})$ samples were extracted with $3 \mathrm{~mL} 80 \%$ acetone for $25 \mathrm{~min}$ in an ultrasonic processor (Vibra-Cell, Sonics and Materials Inc., Danbury, CT). The absorbance (A) of the extract was read at $663 \mathrm{~nm}, 645$ $\mathrm{nm}$ and $470 \mathrm{~nm}$ in a microplate reader (Synergy H1, BioTek, Winooski, VT).

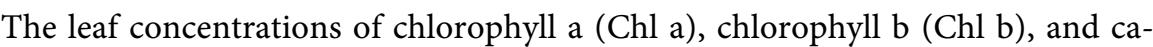
rotenoids in the extracts were estimated using the following relationships:

$$
\begin{gathered}
\text { Chl } \mathrm{a}=12.72 \mathrm{~A} 663-2.59 \mathrm{~A} 645 \\
\mathrm{Chl} \mathrm{b}=22.88 \mathrm{~A} 645-4.567 \mathrm{~A} 663 \\
\text { Total Chl } \mathrm{a}+\mathrm{b}=20.3 \mathrm{~A} 645+7.22 \mathrm{~A} 663 \\
\text { Carotenoids }=(1000 \mathrm{~A} 470-3.27 \mathrm{Chl} \mathrm{a}-104 \mathrm{Chl} \mathrm{b}) / 229
\end{gathered}
$$

\subsection{Anthocyanins}

Lettuce leaf anthocyanins were extracted as outlined by Nakata et al. [21] with some modifications. Ground freeze-dried lettuce leaf samples $(0.02 \mathrm{~g})$ were extracted twice with $0.5 \mathrm{~mL}$ of extraction buffer [methanol:acetic acid-45:5 v/v] using an ultrasonic processor (Vibra-Cell, Sonics and Materials Inc., Danbury, $\mathrm{CT})$. The supernatants were centrifuged at $12,000 \mathrm{x}$ g for $5 \mathrm{~min}$ and the absorbance of supernatants was measured at 530 and $657 \mathrm{~nm}$ in a microplate reader (Synergy H1, BioTek, Winooski, VT, USA). Concentrations of anthocyanin in leaves were calculated using the following relationship: (Abs530/g D.W.) = [Abs530 $-(0.25 \times$ Abs657) $\times 25$. The anthocyanin concentration was expressed on a dry weight basis.

\subsection{Total Phenolic Concentration and Antioxidants Capacity}

The concentration of total phenolic compounds was determined using the modified Folin-Ciocalteu reagent method [22]. Ground freeze-dried lettuce leaf (0.04 $\mathrm{g}$ ) and tomato fruit samples $(0.4 \mathrm{~g})$ were extracted in $4 \mathrm{~mL}$ of $80 \%$ acetone using an ultrasonic processor (Vibra-Cell, Sonics and Materials Inc., Danbury, CT) for 
$20 \mathrm{~min}$. A $1.5 \mathrm{~mL}$ aliquot of the extract was transferred to a centrifuge tube and kept in the darkness overnight at $4^{\circ} \mathrm{C}$. The extract was then centrifuged at 1000 rpm for $2 \mathrm{~min}$ and a $50 \mu \mathrm{L}$ of the supernatant was mixed with $135 \mu \mathrm{L}$ of distilled water, $750 \mu \mathrm{L}$ of diluted (1:10) Folin-Ciocalteu reagent (Sigma-Aldrich, St. Louis, MO, USA), and $600 \mu \mathrm{L}$ of $7.5 \%$ (w/v) $\mathrm{Na}_{2} \mathrm{CO}_{3}$. The mixture was vortexed and incubated in a water bath at $45^{\circ} \mathrm{C}$ for $15 \mathrm{~min}$ and was then allowed to cool at room temperature. The absorbance of the mixture was read at $765 \mathrm{~nm}$ (U-1100 Spectrophotometer, Hitachi Ltd. Tokyo, Japan). Gallic acid standards were prepared (Acros Organics, Fair Lawn, NJ) in 80\% acetone with 3 replicates for each concentration. The amount of total phenolic concentration was quantified as gallic acid equivalent (GAE) on a dry weight basis.

ABTS (aminobenzotriazole) decolorization assay was used to determine the total antioxidant capacity as outlined by Miller and Rice-Evans [23] and Pennycooke et al. [24]. A $2.5 \mathrm{mM}$ ABTS stock solution was used to generate $\mathrm{ABTS}^{*}$ radical cations by adding $0.4 \mathrm{~g}$ of $\mathrm{MnO}_{2}$ as an oxidizing agent and stirring continuously at room temperature. Excess $\mathrm{MnO}_{2}$ was removed by filtering under vacuum first, and then using $0.22 \mu \mathrm{m}$ syringe end filter. Then, the ABTS* solution was diluted to an absorbance value of $0.7( \pm 0.05)$ at $730 \mathrm{~nm}$ by using $5 \mathrm{mM}$ PBS (phosphate buffer saline) at $\mathrm{pH}$ 7.4 and stored in water bath at $30^{\circ} \mathrm{C}$. One $\mathrm{mL}$ of $\mathrm{ABTS}^{\star}$ reagent was added to Trolox (6-Hydroxy-2,5,7,8-tetramethylchroman-2-carboxylic acid) standards or samples and vortexed for $10 \mathrm{~s}$ and followed by $1 \mathrm{~min}$ of reaction time. The absorbance of the reaction mixture was measured at $730 \mathrm{~nm}$. A PBS solution was used as a blank for each assay. The antioxidant capacity of samples was estimated as the Trolox equivalent.

\subsection{Individual Phenolic Compounds}

Freeze-dried and ground lettuce leaf and tomato samples $(0.1 \mathrm{~g}$ and $0.4 \mathrm{~g}$, respectively) were extracted overnight with $10 \mathrm{~mL}$ of $70 \%$ aqueous methanol on an orbital shaker (Benchmark, Edison, NJ) in the dark. The extract was centrifuged to collect the supernatant and the residue was further washed twice with methanol and centrifuged to get the final supernatant volume of $30 \mathrm{~mL}$. A $2 \mathrm{~mL}$ aliquot of the supernatant was evaporated to dryness under streaming nitrogen gas, and the residue was re-dissolved in $1 \mathrm{~mL}$ of $70 \%$ methanol and then filtered through $0.22 \mu \mathrm{m}$ syringe end filter (MilliporeSigma, Burlington, MA). The phenolic compounds were quantified using a Shimadzu HPLC system (Kyoto, Japan) consisting of a DGU-20A3 degasser, an LC-20AB liquid delivery pump, a SIL-20ACHT auto-sampler, a CTO-20AC column oven, and a UV/V is detector (180 - $800 \mathrm{~nm})$. A C18 reversed phase column $(250 \mathrm{~mm} \mathrm{~L} \times 4.6 \mathrm{~mm} \mathrm{D}$, Waters, Milford, MA) was used to separate the phenolic compounds. The elution was conducted with a mobile phase A consisting of $5 \%$ formic acid in deionized water and mobile phase B consisting of 5\% formic acids in $95 \%$ methanol at a rate of $0.8 \mathrm{~mL} / \mathrm{min}$ and $31^{\circ} \mathrm{C}$ oven temperature. The gradient used for solvent $\mathrm{B}$ was $0 \%-10 \%$ for $5 \mathrm{~min}, 10 \%-40 \%$ for $25 \mathrm{~min}, 40 \%-70 \%$ for $10 \mathrm{~min}$, and $70 \%$ for 
16 min before returning to $0 \%$. The data were analyzed using the Shimadzu LC Solution Software (Kyoto, Japan). Concentrations of phenolic acids (gallic acid, chlorogenic acid, caffeic acid, and chicoric acid) and flavonoids [luteolin-7-glu (glucoside), quercetin-2-glu, apigenin-3-glu, and kampferol-3-glu] were expressed as equivalents of vanillic acid and quercetin, respectively.

\subsection{Individual Carotenoids}

Accumulation of individual carotenoids was measured in tomato fruits from plants subjected to supplemental UV treatments. Samples from freeze-dried and ground fruit pericarp at breaker and fully ripe stages $(0.3 \mathrm{~g})$ were extracted with $6 \mathrm{~mL}$ of extraction solution (ethanol: hexane, 4:3, v/v) on an orbital shaker for 4 h. The extract was centrifuged in an Eppendorf centrifuge at $3950 \mathrm{rpm}$ at $20^{\circ} \mathrm{C}$ for $30 \mathrm{~min}$. The supernatant was collected, and the residue was re-extracted with $8 \mathrm{~mL}$ of hexane twice. The collected supernatant was washed with $30 \mathrm{~mL}$ distilled water first, and then $30 \mathrm{~mL}$ of $10 \%$ sodium chloride $(\mathrm{NaCl})$ solution several times. The lipid layer was collected and $2 \mathrm{~mL}$ of this was evaporated in an Eppendorf vacufuge (Concentrator 5301, Hamburg, Germany) to dryness and was re-dissolved in $2 \mathrm{~mL}$ of methanol:MTBE (methyl tert-butyl ether)-1:1, v/v. The resulting solution was filtered through a $0.22 \mu \mathrm{m}$ membrane filter before the HPLC analyses. All the extraction procedures were conducted under dim light in a transfer hood.

Carotenoids were separated and quantified using Shimadzu HPLC system (Kyoto, Japan) as described above using a YMC C30 reversed phase column. The mobile phase consisted of methanol:MTBE (7:3, v/v, Solvent A) and MTBE (100\% Solvent B). The gradient of elution for solvent B was as follows: $0 \%$ to $10 \%$ in $6 \mathrm{~min}, 10 \%$ to $20 \%$ in $16 \mathrm{~min}, 20 \%$ to $70 \%$ in $26 \mathrm{~min}, 70 \%$ to $10 \%$ in 36 $\mathrm{min}$. The carotenoids (lutein, $\beta$-carotene, and lycopene) were quantified at 450 $\mathrm{nm}$ using Shimadzu LC Solution Software (Kyoto, Japan).

\subsection{Essential Nutrients}

Lyophilized and powdered lettuce leaf and tomato samples $(0.15 \mathrm{~g})$ were used to measure concentrations of essential nutrients. Concentrations of total carbon and nitrogen were determined using a LECO TruSpec CN combustion analyzer. Protein concentrations were derived from the leaf nitrogen concentrations using a conversion factor of 6.25 [25]. The concentrations of nutrients, including phosphorus, potassium, calcium, magnesium, sulfur, copper, iron, manganese, and zinc, were determined using an inductively coupled plasma (ICP) spectrometer (Model 720-ES ICP Optical Emission Spectrometer, Varian, Australia PTY Ltd., Australia).

\subsection{Statistical Analysis}

Data on the treatment effects were analyzed using one-way Analysis of Variance (ANOVA) (SAS 9.4, Cary, NC and XLSTAT, Addinsoft, New York, NY) and the 
treatment means were compared using the Duncan's multiple range test at $\mathrm{p}<$ $0.05,<0.01$, and $<0.001$.

\section{Results and Discussion}

\subsection{Lettuce}

\subsubsection{Growth}

The UV treatments were imposed on the red leaf "New Red Fire" and green leaf "Two Star" varieties 5 days prior to harvest (Table 1). Shoot and root biomasses of lettuce plants were determined after harvest. UV treatments did not affect the fresh or dry shoot biomass in both lettuce varieties (Table 2). However, root biomass was affected by the UV treatment and was variety dependent.

In "New Red Fire", both fresh and dry weights of root biomass were reduced by all the UV treatments, while, on the contrary, the fresh weights of roots in "Two Star" increased due to UV-B treatment but with no effect on their dry weights by any UV treatments. Although shoot mass was not affected by UV treatments in both varieties, plants in "New Red Fire" were smaller under UV-B and UV-AB treatments because of their reduced leaf area. The total leaf area of these plants was about $86 \%$ or less relative to the control plants (Figure 1). Krizek et al. [26] examined the impact of solar UV radiation on red-leaf lettuce (cv. New Red Leaf) and found that both UV-A and UV-B reduced both fresh and dry weights of shoots. In our study, UV-B seems to have a negative impact on the growth of lettuce plants. Similar observations have also been made by others

Table 2. Shoot and root fresh and dry weights for lettuce varieties, "New Red Fire" (NRF) and "Two Star" (TS), subjected to supplemental UV radiation for 5 days before harvest. Control plants did not receive UV radiation.

\begin{tabular}{|c|c|c|c|c|c|}
\hline & & \multicolumn{2}{|c|}{ Shoot } & \multicolumn{2}{|c|}{ Root } \\
\hline & & FW (g/plant) & DW (g/plant) & FW (g/plant) & DW (g/plant) \\
\hline \multirow{5}{*}{ New Red Fire } & Control & 71.14 & 5.20 & $16.46 \mathrm{a}$ & $1.18 \mathrm{a}$ \\
\hline & UV-A & 82.38 & 5.32 & $9.82 \mathrm{~b}$ & $0.75 \mathrm{~b}$ \\
\hline & UV-B & 62.93 & 5.33 & $10.85 \mathrm{~b}$ & $0.71 \mathrm{~b}$ \\
\hline & UV-AB & 61.81 & 4.91 & $10.33 \mathrm{~b}$ & $0.79 \mathrm{~b}$ \\
\hline & Significance & NS & NS & ** & * \\
\hline \multirow{5}{*}{ Two Star } & Control & 67.42 & 5.83 & $11.18 \mathrm{~b}$ & 0.76 \\
\hline & UV-A & 72.64 & 5.68 & $13.57 \mathrm{ab}$ & 1.05 \\
\hline & UV-B & 69.93 & 5.76 & $17.35 \mathrm{a}$ & 1.13 \\
\hline & UV-AB & 73.93 & 11.96 & $11.96 \mathrm{~b}$ & 1.02 \\
\hline & Significance & NS & NS & * & NS \\
\hline
\end{tabular}

Significant differences are indicated by ${ }^{*}$ and ${ }^{* *}$ at $\mathrm{p}<0.05$ and $\mathrm{p}<0.01$, respectively $(\mathrm{n}=4)$. NS indicates lack of significant differences. Means followed by same letter(s) in a column are not significantly different. 


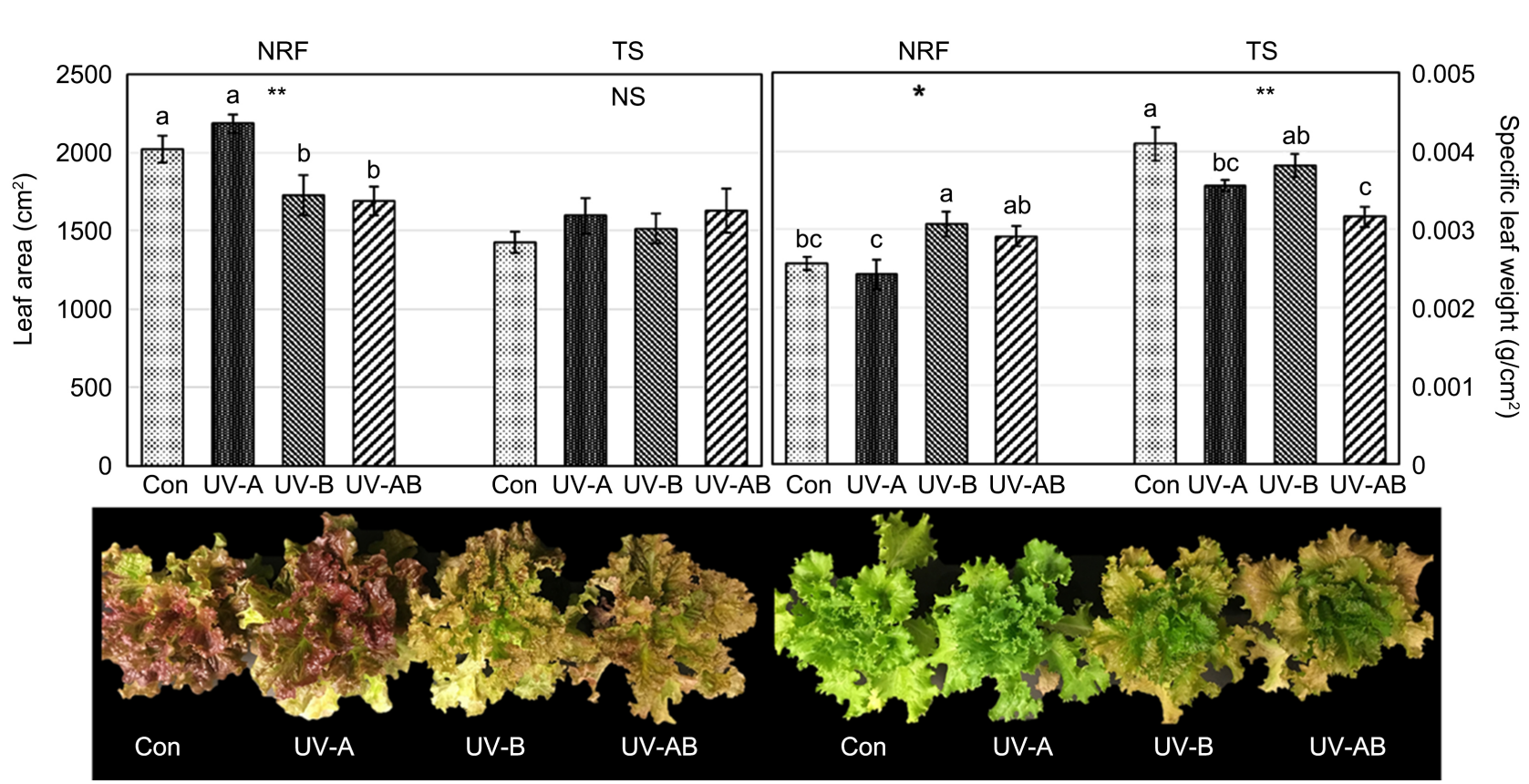

Figure 1. Upper panel: The effects of the supplemental UV treatments on the leaf area and specific leaf weights for "New Red Fire" (NRF) and "Two Star" (TS) measured at the time of harvest. Control (con) plants did not receive any supplemental UV. Significant differences are indicated by ${ }^{*}$ and ${ }^{* *}$ at $\mathrm{p} \leq 0.05$ and $\mathrm{p} \leq 0.01$, respectively. NS indicates lack of significant differences. Bars (treatment means + SE) with the same letter(s) show no significant treatment differences within a variety. Bottom panel: Growth characteristics of control and UV treated red (left) and green lettuce (right) plants at the time of harvest.

who found that high UV-B intensity reduced growth, including plant height, fresh and dry biomass, leaf area, and the relative growth rate in maize (Zea mays L.) and sunflower (Helianthus annuus L.) [27] [28]. Caldwell et al. [29] argued that plants' sensitivity to UV-B may depend on the spectral balance between visible and UV-A radiation. They found that shoot growth was reduced by UV-B only when visible and UV-A radiation levels were low in soybean (Glycine max Merr.) plants. When only visible light was low, UV-A appeared to mitigate the adverse effects of UV-B, but not in the presence of high levels of visible light. In our study, although supplemental UV-A had no impact on the leaf area in red leaf lettuce, supplemental UV-B and UV-AB reduced the total leaf area (Figure 1). However, no significant impact of supplemental UV on the leaf area was observed in green leaf lettuce. The specific leaf weight (i.e., leaf dry mass/unit area) in red leaf lettuce was higher in response to supplemental UV-B, although it resulted in reduced total leaf area compared to the control plants indicating that UV-B treated plants produced denser leaves. Denser leaves may be a defensive response as it can reduce the penetration of UV-B into the leaves. However, in green leaf lettuce, both supplemental UV-A and UV-AB treatments reduced the leaf specific weight, although there was no significant impact on the total leaf area by these treatments.

\subsubsection{Chlorophyll, Carotenoids, and Anthocyanins}

Leaf chlorophyll a concentration did not change in "New Red Fire" lettuce with UV treatments while chlorophyll b level increased slightly with UV-AB treat- 
ment (Table 3). However, in "Two Star", UV treatments did not have any effect on the concentrations of both chlorophyll a and chlorophyll b. Similarly, leaf carotenoid levels were unaltered due to UV treatments in both lettuce varieties. With regard to leaf anthocyanin levels, UV treatments had no effect in "New Red Fire" while there was an increase (44.2\%) in "Two Star" due to UV-B treatment compared to the control plants (Figure 2). Similar observations were noted in lettuce in response to supplemental UV by Li and Kubota [30]. Other studies have also found similar response to UV-B in red leaf lettuce [5] [26]. However, control plants of red leaf variety "New Red Fire" had higher anthocyanin concentration relative to their counterparts in the green leaf variety "Two Star". Exposure of lettuce plants to either UV-B or UV-AB tended to produce leaf discoloration (Figure 2). This may be due to longer exposure of plants to these treatments. The negative impact of UV-B is expected, because of its relative high energy compared UV-A. Similar negative impacts of UV-B on leaf pigments have been reported in other plant species [31].

\subsubsection{Phytochemicals}

Both the total phenolic concentration and antioxidant capacity in "New Red Fire" increased in response to supplemental UV-A while they were unaltered in response to both supplemental UV-B and UV-AB (Figure 3). Similar results have been reported in lettuce where both UV-A and UV-B induced higher accumulation of total phenolic compounds and the antioxidant capacity in lettuce and dropwort [32] [33]. In our study, only supplemental UV-A was found to have a positive impact on the concentration of total phenolic coounds in "New Red Fire" lettuce but not in "Two Star" lettuce. The total phenolic concentration and antioxidant capacity in leaves of "New Red Fire" increased by more than $56 \%$ and $86 \%$, respectively, due to supplemental UV-A treatment compared to the control plants. However, no significant changes in either total phenolic concentration or antioxidant capacity were noted in green leaf "Two Star" due to supplemental UV treatments.

Table 3. Concentrations of chlorophyll a and b, total chlorophyll, and carotenoids in the leaves of "New Red Fire" (NRF) and "Two Star" (TS) subjected to supplemental UV radiation treatments. Measurement were made at the time of harvest.

\begin{tabular}{|c|c|c|c|c|c|c|c|c|}
\hline & \multicolumn{4}{|c|}{ New Red Fire } & \multicolumn{4}{|c|}{ Two Star } \\
\hline & Chl a & Chl b & Total Chl & Carotenoid & $\mathrm{Chl} \mathrm{a}$ & Chl b & Total Chl & Carotenoid \\
\hline & \multicolumn{4}{|c|}{$(\mu \mathrm{g} / \mathrm{g} D W)$} & \multicolumn{4}{|c|}{$(\mu \mathrm{g} / \mathrm{g} D W)$} \\
\hline Control & 161.2 & $4.77 \mathrm{bc}$ & 215.8 & 0.76 & 253.6 & 4.78 & 339.5 & 1.33 \\
\hline UV-A & 202.6 & $4.59 \mathrm{c}$ & 267.9 & 0.98 & 288.4 & 4.80 & 386.8 & 1.38 \\
\hline UV-B & 165.3 & $4.99 \mathrm{ab}$ & 224.4 & 0.86 & 267.2 & 5.01 & 363.4 & 1.37 \\
\hline UV-AB & 113.8 & $5.18 \mathrm{a}$ & 157.1 & 0.59 & 278.4 & 4.96 & 377.4 & 1.46 \\
\hline Significance & NS & ** & NS & NS & NS & NS & NS & NS \\
\hline
\end{tabular}

Significant differences are indicated by ${ }^{\star}$ and ${ }^{* *}$ at $\mathrm{p}<0.05$ and $\mathrm{p}<0.01$, respectively $(\mathrm{n}=4)$. NS indicates lack of significant differences. Means followed by the same letter(s) in a column are not significantly different. 


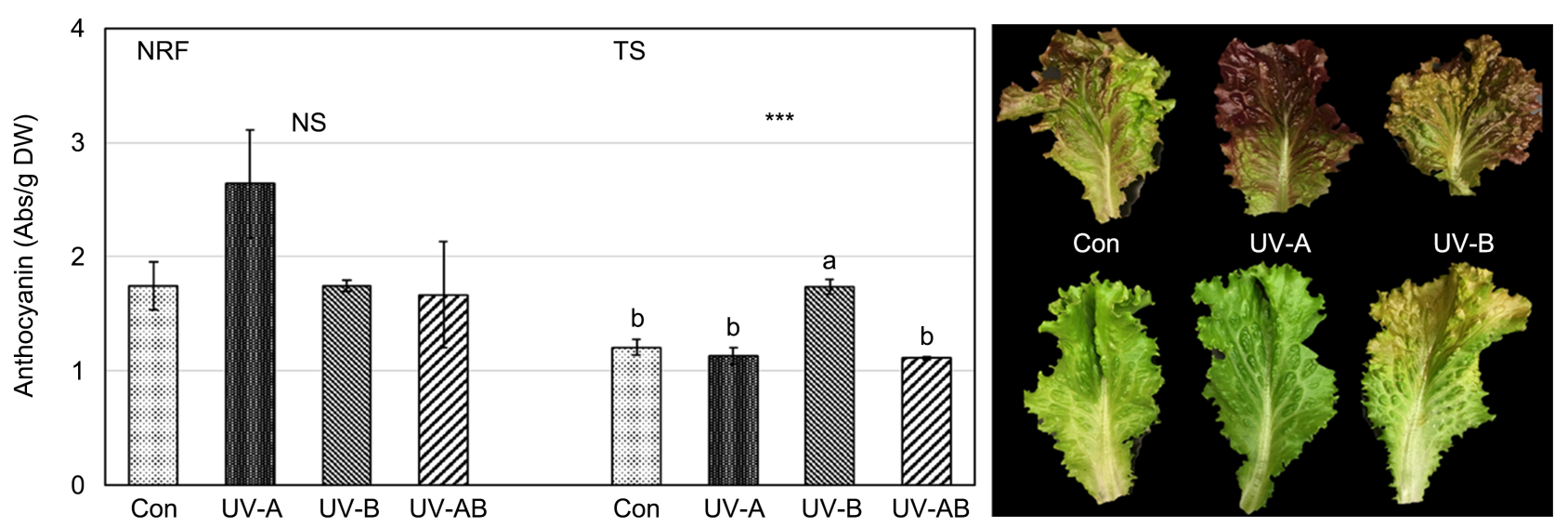

Figure 2. Anthocyanin concentrations in the leaves at the time of harvest in "New Red Fire" (NRF) and "Two Star" (TS) subjected to supplemental UV radiation. Photographs on the right show leaf color of red (top row) and green (bottom row) lettuce treated with supplemental radiation. Control (con) plants did not receive any supplemental UV treatment. Bars (treatment means + SE) with the same letter (s) show no significant treatment differences within a variety. Significant difference is indicated by ${ }^{\star * \star}$ at $\mathrm{p}<$ 0.001 . NS indicates lack of significant difference.

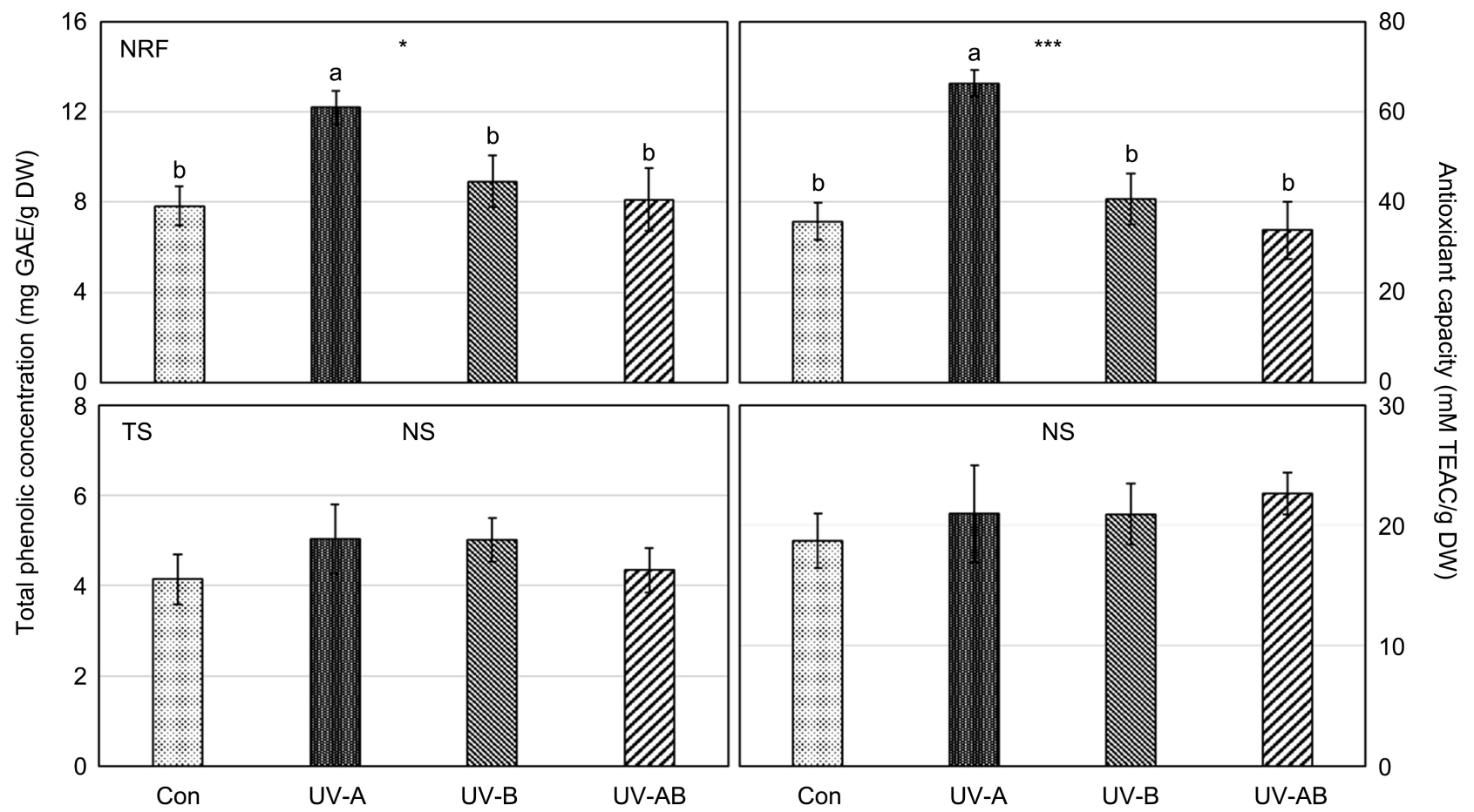

Figure 3. Total phenolic concentration and antioxidant capacity at the time of harvest in "New Red Fire" (NRF) and "Two Star" (TS) subjected to supplemental UV radiation. Control (con) plants did not receive any supplemental UV treatment. Bars (treatment means + SE) with the same letter (s) show no significant treatment differences within a variety. Significant differences are indicated by ${ }^{*}$ and ${ }^{* *}$ at $\mathrm{p}<0.5$ and $\mathrm{p}<0.001$, respectively. NS indicates lack of significant differences.

Of the phytochemicals examined, chicoric acid was the dominant phenolic compound in both lettuce varieties irrespective of the supplemental UV treatments, (Figure 4). Lettuce is rich in chicoric acid, which is an important health-promoting phytochemical known to play a significant role in fighting immune suppressing viral infections including HIV-1 [34]. Supplemental UV-A 

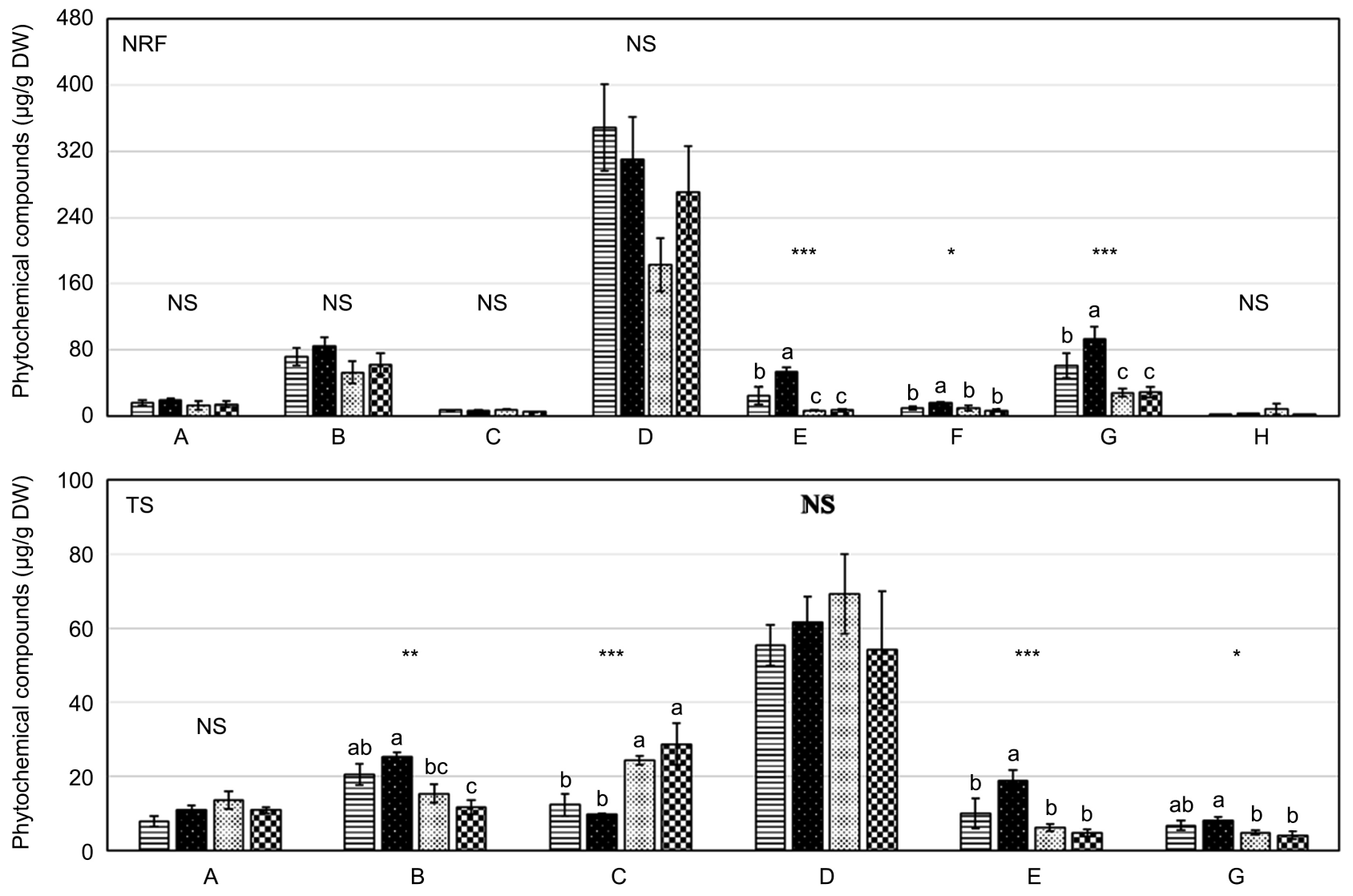

Figure 4. Individual phenolic compounds at the time of harvest in "New Red Fire" (NRF) and "Two Star" (TS) subjected to supplemental UV radiation. Control (con) plants did not receive any supplemental UV treatment. Phenolic compounds included gallic acid (A), chlorogenic acid (B), caffeic acid (C), chicoric acid (D), luteolin-7-glucoside (glu) (E), quercetin-3-glu (F), apigenin-3-glu (G), kaempferol-3-glu (H). Bars (treatment means + SE) with the same letter(s) show no significant treatment differences. Significant differences are indicated by ${ }^{*},{ }^{* *}$ and ${ }^{* * *}$ at $\mathrm{p}<0.05, \mathrm{p}<0.01$, and $\mathrm{p}<0.001$, respectively. NS indicates lack of significant differences.

treatment produced sharp increases in the concentration of luteolin-7-glu (121\%), quercetin-3-glu (68\%), and apigenin-3-glu (54\%) in the leaves of red leaf "New Red Fire" over the control. However, on the contrary, exposure of these plants to UV-B and UV-AB lowered the accumulations of luteolin-7-glu and apigenin-3-glu. Also, in "Two Star", UV-A treatment produced higher accumulations of luteolin-7-glu. However, UV-AB treatment decreased the concentration of chlorogenic acid compared to the control. Overall, in "New Red Fire", supplemental UV-A had a more positive impact in enhancing the accumulation of many flavonoids while supplemental UV-B and UV-AB had a negative impact on the accumulation of these flavonoids. Although the response of phenolic compounds to supplemental UV-A and UV-B radiation in lettuce were variable, the results from our study show that UV radiation plays a role in improving the accumulation of many phenolic compounds and thus enhancing the health-promoting qualities of lettuce [13]. Krizek et al. [26] found that in red leaf lettuce both UV-A and UV-B enhanced the concentration of UV absorbing compounds in plants, presumably flavonoids and other phenolic compounds 
which are known to have a protective function against UV radiation in plants [35]. Similarly, in red leaf lettuce the photosynthetic function is higher in the presence of UV radiation than in its absence suggesting that higher accumulation of phenolic compounds under UV may have a protective function on the photosynthetic apparatus [5]. Krizek et al. [26] suggested that UV-B is more active in the induction of flavonoids than UV-A in red leaf lettuce. This is further supported by a study by Morales et al. [36] where UV-B exclusion showed a decreased accumulation of many flavonoids in silver birch ( $B$. pendula Roth) with lower expression of PAL (phenylalanine ammonia-lyase) gene in the leaves, which codes for the key gateway enzyme in the synthesis of phenolic compounds.

\subsubsection{Essential Nutrients}

Red leaf "New Red Fire" lettuce (control) was nutrient dense compared to green leaf "Two Star" lettuce. It had higher concentrations of all the essential nutrients examined in this study (Table 4). For example, the level of proteins in the leaves of "New Red Fire" lettuce was more than 34\% higher relative that of "Two Star" lettuce. In addition, levels of many mineral nutrients, such as potassium, magnesium, sulfur, copper, manganese, and zinc, in red leaf lettuce were higher relative to those in green leaf lettuce. In particular, accumulation of copper, zinc, and manganese were notably higher in red leaf "New Red Fire" lettuce relative the green leaf lettuce. The amount of copper, zinc, and manganese in red leaf lettuce was approximately $48 \%, 41 \%$ and $31 \%$ higher, respectively, compared to that in the green leaf lettuce.

We examined the impact of UV treatments on the accumulation of essential nutrients in the leaves of red and green leaf lettuce varieties. In response to supplemental UV, leaf calcium and magnesium levels increased in "New Red Fire" due to UV-A treatment while UV-A and UV-B treatments resulted in higher magnesium levels compared to the control plants (Figure 5). However, accumulations of other essential nutrients were not affected by UV treatments in "New Red Fire" lettuce. In contrast, accumulations of most nutrients in "Two Star" were higher with UV treatment relative to the control plants with exception carbon and iron (Figure 6 and Table 5). The accumulation of iron did not change with any UV treatment while carbon accumulation decreased in response to supplemental UV-B and UV-AB (Table 5). This suggests that photosynthetic activity can be adversely affected, especially by UV-B which is often reflected in reduced overall poor plant growth [8].

Table 4. Concentrations of essential nutrients in leaves of "New Red Fire" (NRF) and "Two Star" (TS) lettuces at the time of harvest. Protein concentration was derived from total the nitrogen concentration in the leaves.

\begin{tabular}{cccccccccccc}
\hline & Protein (\%) & $\mathrm{C}(\%)$ & $\mathrm{P}(\%)$ & $\mathrm{K}(\%)$ & $\mathrm{Ca}(\%)$ & $\mathrm{Mg}(\%)$ & $\mathrm{SO}_{4}-\mathrm{S}(\%)$ & $\mathrm{Cu}(\mathrm{ppm})$ & $\mathrm{Fe}(\mathrm{ppm})$ & $\mathrm{Mn}(\mathrm{ppm})$ & $\mathrm{Zn}(\mathrm{ppm})$ \\
\hline $\mathrm{NRF}$ & 14.63 & 38.83 & 0.54 & 5.74 & 0.90 & 0.40 & 0.20 & 2.94 & 112.1 & 87.66 & 43.74 \\
$\mathrm{TS}$ & 10.88 & 38.69 & 0.29 & 4.01 & 0.83 & 0.26 & 0.14 & 1.98 & 96.4 & 59.7 & 25.4 \\
\hline
\end{tabular}




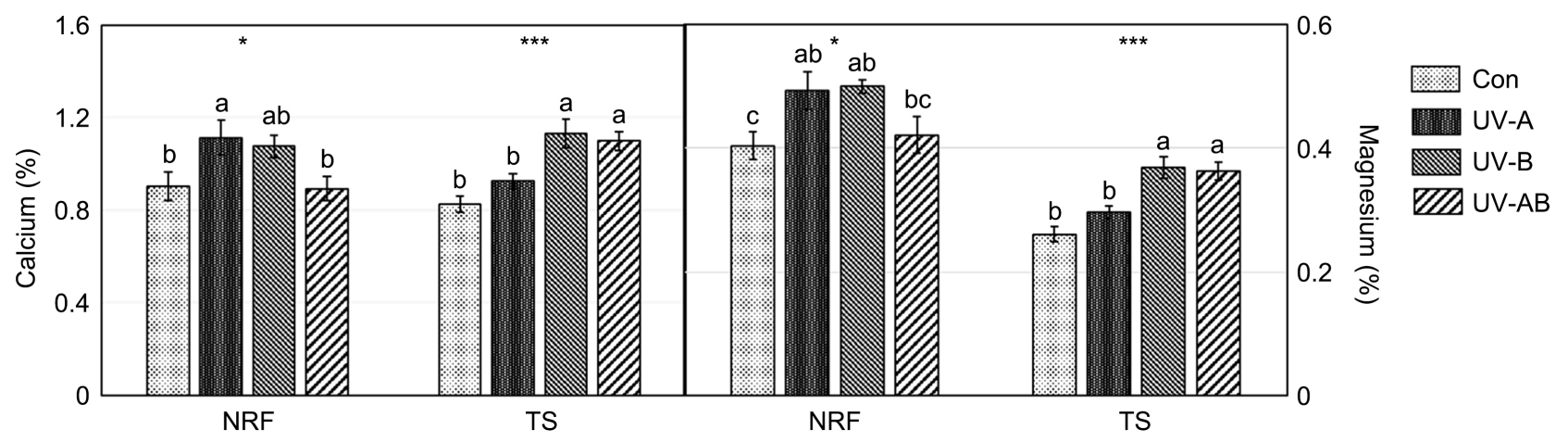

Figure 5. Concentrations of calcium and magnesium in leaves at the time of harvest in "New Red Leaf" (NRF) and "Two Star" (TS) lettuce subjected to supplemental UV radiation. Control (con) plants did not receive any supplemental UV treatment. Bars (treatments $+\mathrm{SE}$ ) with the same letter(s) show no significant treatment differences. Significant differences are indicated by * and $* * *$ at $\mathrm{p}<0.05$ and $\mathrm{p}<0.001$, respectively.
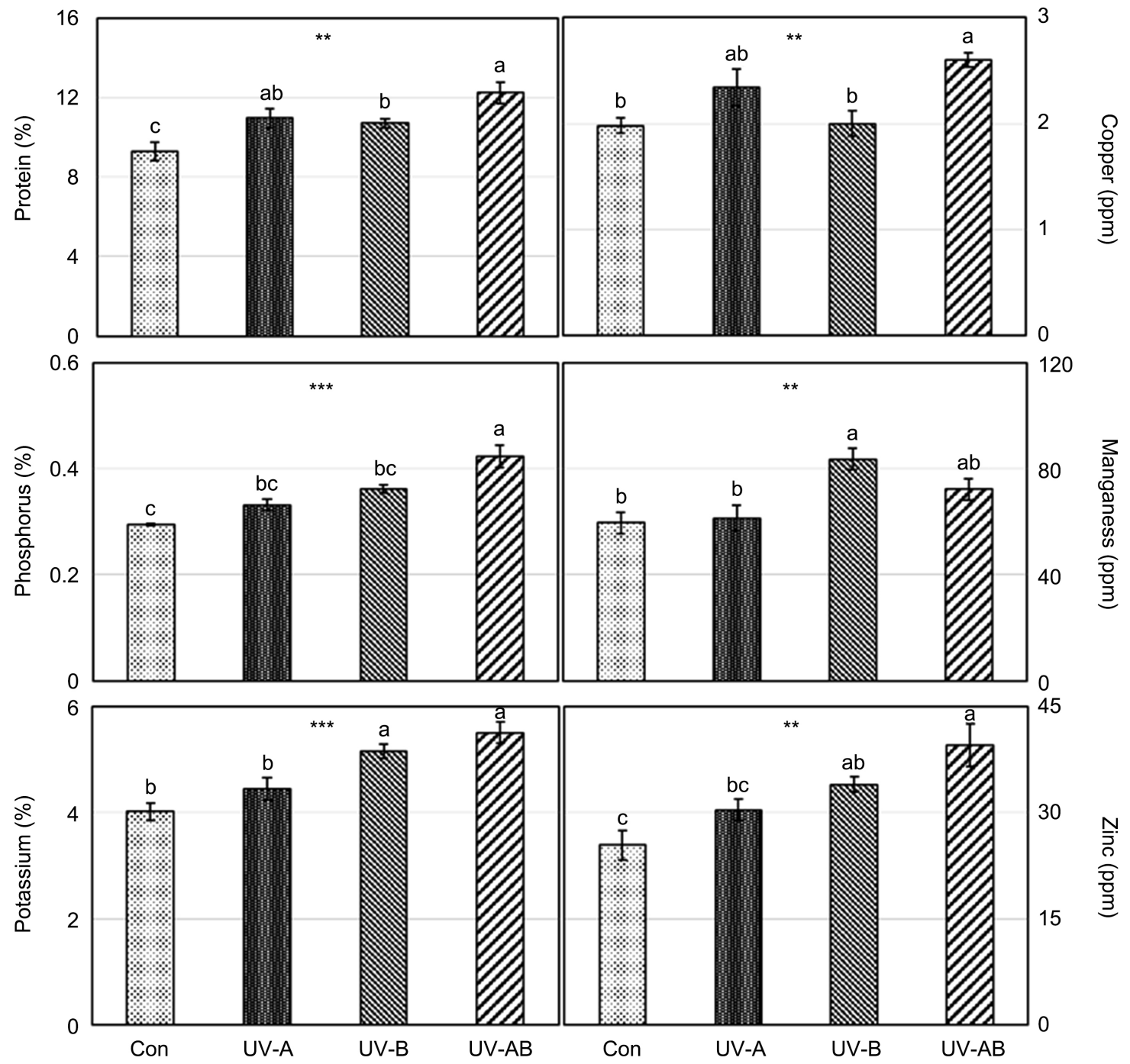

Figure 6. Concentrations of essential nutrients in leaves of "Two Star" (TS) lettuce subjected to supplemental UV radiation at the time of harvest. Control (con) plants did not receive any supplemental UV treatment. Protein concentration was derived from total nitrogen in the leaves. Bars (treatments + SE) with the same letter(s) show no significant treatment differences. Significant differences are indicated by ${ }^{* *}$ and ${ }^{* *}$ at $\mathrm{p}<0.01$ and $\mathrm{p}<0.001$, respectively. 
Table 5. Concentrations of carbon, sulfur, and iron in leaves of "Two Star" (TS) at the time of harvest in subjected to supplemental UV radiation.

\begin{tabular}{cccc}
\hline & & Two Star & \\
\cline { 2 - 4 } & $\mathrm{C}(\%)$ & $\mathrm{SO}_{4}-\mathrm{S}(\%)$ & $\mathrm{Fe}(\mathrm{ppm})$ \\
\hline Control & $38.69 \mathrm{a}$ & $0.14 \mathrm{c}$ & 96.4 \\
UV-A & $39.00 \mathrm{a}$ & $0.17 \mathrm{~b}$ & 111.1 \\
UV-B & $37.54 \mathrm{~b}$ & $0.19 \mathrm{~b}$ & 100.0 \\
UV-AB & $37.62 \mathrm{~b}$ & $0.21 \mathrm{a}$ & 150.3 \\
Significance & $* *$ & $* * *$ & $\mathrm{NS}$ \\
\hline
\end{tabular}

Significant differences are indicated by ${ }^{* *}$ and ${ }^{* * *}$ at $\mathrm{p}<0.01$ and $\mathrm{p}<0.001$, respectively $(\mathrm{n}=4)$. NS indicates lack of significant differences. Means followed by same letter(s) in a column are not significantly different.

Exposure of "Two Star" to all the UV treatments resulted in higher accumulation of protein and sulfur in the leaves compared to the control (Figure 6 and Table 5). The increase in protein accumulation in the leaves ranged from 17 to $31 \%$, with UV-AB producing the largest increase relative to the control plants. In addition, supplemental UV-B treatment increased the accumulation of protein, phosphorus, potassium, calcium, magnesium, sulfur, manganese, and zinc, while supplemental UV-AB had a much stronger response in enhancing the accumulation of many nutrients including protein, phosphorus, potassium, sulfur, copper and zinc. UV-AB enhanced the concentration of phosphorus by $44 \%$, potassium by $37 \%$, copper by $31 \%$, and zinc by $55 \%$ in leaves of "Two Star" lettuce over the control plants. Although all the UV treatments have a positive role in enhancing many essential nutrients, UV-AB was most effective in improving the nutritional quality of green leaf lettuce with regard to the essential nutrients. This indicates that both UV-A and UV-B, which are components of solar radiation, are essential for improving the nutritional quality of food we consume. From the perspective of mitigating the major nutrient deficiencies in the human diet, many of these nutrients, especially protein, play an important role. For example, treating green leaf "Two Star" lettuce with supplemental UV-AB can increase the accumulation of protein by $31 \%$. Protein is an important nutrient in human diet and its deficiency is widely prevalent in numerous countries in the world, especially in developing countries [37]. Approximately $43 \%$ of children (230 million) are afflicted by protein-energy deficiency, which can lead to serious health issues including loss of muscle mass, higher risk for bone fracture, edema, fatty liver disease, and many more diseases [38].

Thus, overall, the results show that supplemental UV can play a significant role in improving nutritional quality with regard to not only health-promoting phenolic compounds but also essential nutrients in lettuce. 


\subsection{Tomato}

\subsubsection{Phytochemicals in Fruits}

Total phenolic concentration and the antioxidant capacity of fully ripe tomato fruits were measured to identify the effects of supplemental UV-A, UV-B, and $\mathrm{UV}-\mathrm{AB}$ in plants grown in a greenhouse. Tomato plants were treated with supplemental UV-A for 6 days and with UV-B and UV-AB for $3 \mathrm{~h}, 6 \mathrm{~h}$ or $9 \mathrm{~h}$ (1.5 $\mathrm{h}$ /day) prior to harvest (Table 1). Supplemental UV-A had no effect on the total phenolic concentration in fully ripe tomato fruits (Figure 7). Similarly, supplemental UV-B treatment for $3 \mathrm{~h}$ or $6 \mathrm{~h}$ did not affect the total phenolic concentration. However, longer exposure to UV-B for $9 \mathrm{~h}$ and UV-AB for $3 \mathrm{~h}$ or $9 \mathrm{~h}$ increased the concentration of total phenolic compounds. Thus, a brief exposure ( 3 h) of plants before harvest using a combination UV-A and UV-B could enhance the total phenolic concentration of tomato fruits. Although there was an increase in the total phenolic concentrations in the fruits due to UV treatments, it was not reflected in an increase in their antioxidant capacity. This is consistent with observations in a study where blocking UV-B in a greenhouse experiment did not affect the antioxidant capacity of tomato fruits in different tomato genotypes [39].

Individual phenolic compounds and carotenoids were measured in tomato fruits at breaker and fully ripe stages to identify the impact of supplemental UV-A, UV-B, and UV-AB in plants grown in a greenhouse. In tomato fruits (pericarp), the dominant phenolic compound was chlorogenic acid of all the phenolic compounds monitored both at the breaker and fully ripe stages (Figure 8). A higher accumulation of chlorogenic acid was found in fruits at breaker stage than at the fully ripe stage. At the breaker stage, supplemental UV generally had a negative impact on the accumulation of caffeic acid and luteolin-7-glu in fruits compared to the control plants. In fact, on the one hand, supplemental UV treatment did not have any positive impact on the concentration of any phenolic compounds examined in fruits at the breaker stage. On the other hand,

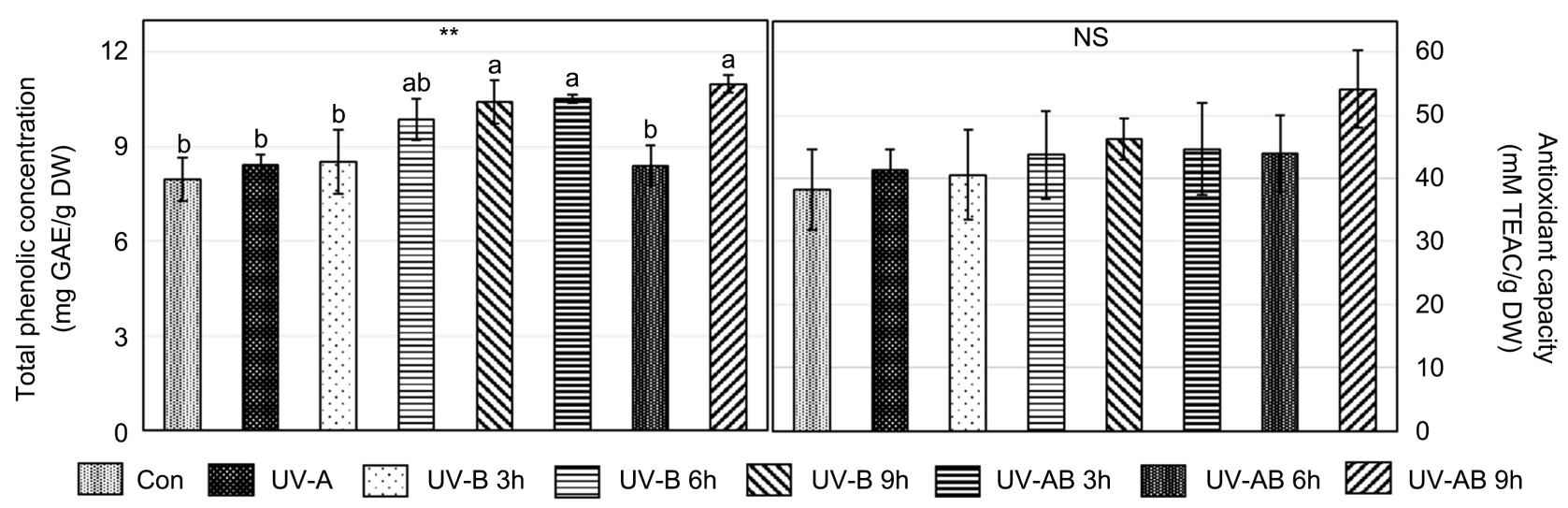

Figure 7. Total phenolic concentration and antioxidant capacity of fully ripe tomato fruits. Plants were treated with supplemental UV-A and UV-B and UV-AB for $3 \mathrm{~h}, 6 \mathrm{~h}$ and $9 \mathrm{~h}$. Control plants (con) did not receive any UV treatment. Bars (SE) with the same letter(s) show no significant treatment differences. Significant difference is indicated by ${ }^{\star *}$ at $\mathrm{p}<0.01$. NS indicates lack of significant differences. 


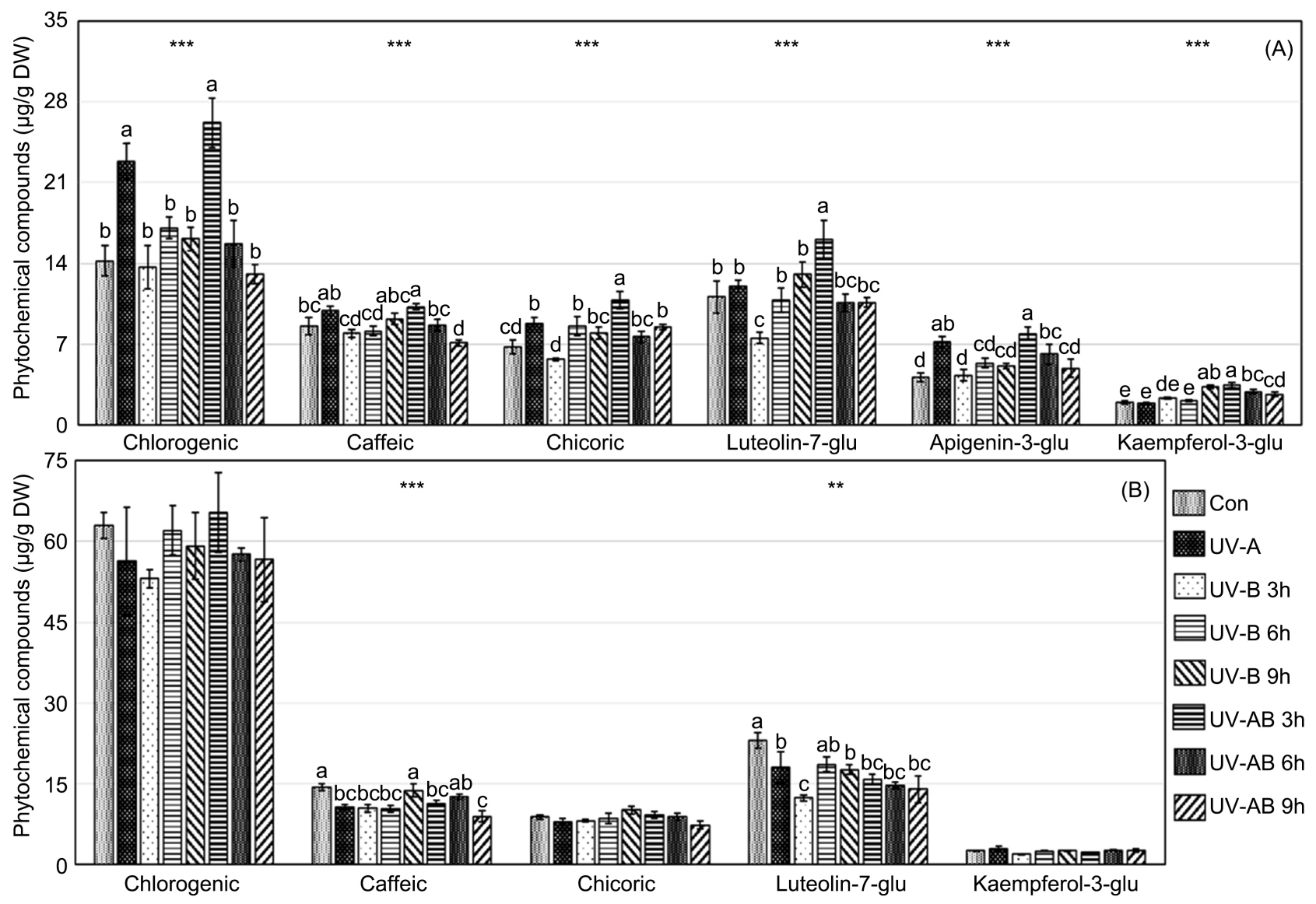

Figure 8. Individual phenolic compounds in tomato fruits. Plants were treated with supplemental UV-A, and UV-B and UV-AB for $3 \mathrm{~h}$ and $6 \mathrm{~h}$. Control plants (con) did not receive any UV treatment. Phenolic compounds included chlorogenic acid, caffeic acid, chicoric acid, luteolin-7-glu, apigenin-3-glu, kaempferol-3-glu in fully ripe (A) and breaker (B) fruits. Bars (SE) with the same letter(s) show no significant treatment differences. Significant differences are indicated by ${ }^{* *}$ and ${ }^{* *}$ at $\mathrm{p}<0.01$ and $\mathrm{p}<$ 0.001 , respectively.

supplemental UV treatment induced higher accumulation of many phenolic compounds when fruits were fully ripe, which is notably a beneficial characteristic with regard to their health-promoting ability in our diet. In fully ripe fruits, supplemental UV treatments induced higher accumulations of a number of phenolic compounds. Treatment of plants with supplemental UV-A or UV-AB (3 h) increased the chlorogenic acid concentration in fully ripe fruits by more than $50 \%$ over the control. Supplemental UV-A also increased the concentrations of chicoric acid and apigenin-3-glu in fully ripe fruits. Generally, supplemental UV-AB (3 h) was more effective in increasing the accumulation of a number of phenolic compounds including chlorogenic acid, caffeic acid, chicoric acid, luteolin-7-glu, apigenin-3-glu, and kaempferol-3-glu. However, in the case kaempferol-3-glu, supplemental UV-B treatment for longer exposure of $9 \mathrm{~h}$ also produced a higher accumulation compared to the control. Overall, higher accumulations of phenolic compounds occurred in fruits at the fully ripe stage when plants were subjected to supplemental UV-AB, especially for short period of time $(3 \mathrm{~h})$.

The accumulation of key carotenoids in tomato fruits at the breaker and fully 
ripe stages in response to supplemental UV treatments is presented in Figure 9. At the breaker stage, exposure of plants to supplemental UV-B and UV-AB for various lengths of time improved the concentration of $\beta$-carotene in fruits but with no impact on the concentration of lutein. There were no detectable levels of lycopene in fruits at the breaker stage. However at the fully ripe stage, supplemental UV-A produced higher concentrations of lutein and $\beta$-carotene in the fruits relative to the control. Also, lutein concentration in fruits was higher in response to supplemental UV-B ( $3 \mathrm{~h}$ ) and to UV-AB at all exposures up to $9 \mathrm{~h}$ compared to the control. Similarly, accumulation of $\beta$-carotene was higher in response supplemental UV-AB ( $3 \mathrm{~h}$ ) compared to the control. Furthermore, an increase in lycopene occurred in ripe fruits in response to UV-AB at only $9 \mathrm{~h}$ exposure. Similar positive results were observed in tomatoes grown in poly-tunnels where fruits contained higher lycopene and $\beta$-carotene concentration with higher UV transmittance [40]. The results from our study suggest that supplemental UV treatment, especially (UV-A and UV-AB), of tomato plants just prior to harvest has a beneficial impact on the accumulations of key carotenoids such as lycopene, lutein and $\beta$-carotene that play an important role in maintaining eye health, in reducing the risks of some cancers, and in maintaining the overall health and wellbeing in humans [41] [42].

\subsubsection{Essential Nutrients in Fruits}

The essential nutrients, including protein, phosphorus, potassium, calcium, magnesium, sulfur, copper, iron, manganese, and zinc, were measured in tomato fruits at breaker and fully ripe stages in response to supplemental UV. Treatment of plants with supplemental UV-A, UV-B, and UV-AB did not produce any significant effect on the accumulation of most of these nutrients examined in this study in fruits at either breaker or fully ripe stage, except for phosphorus in fully ripe fruits (Table 6).

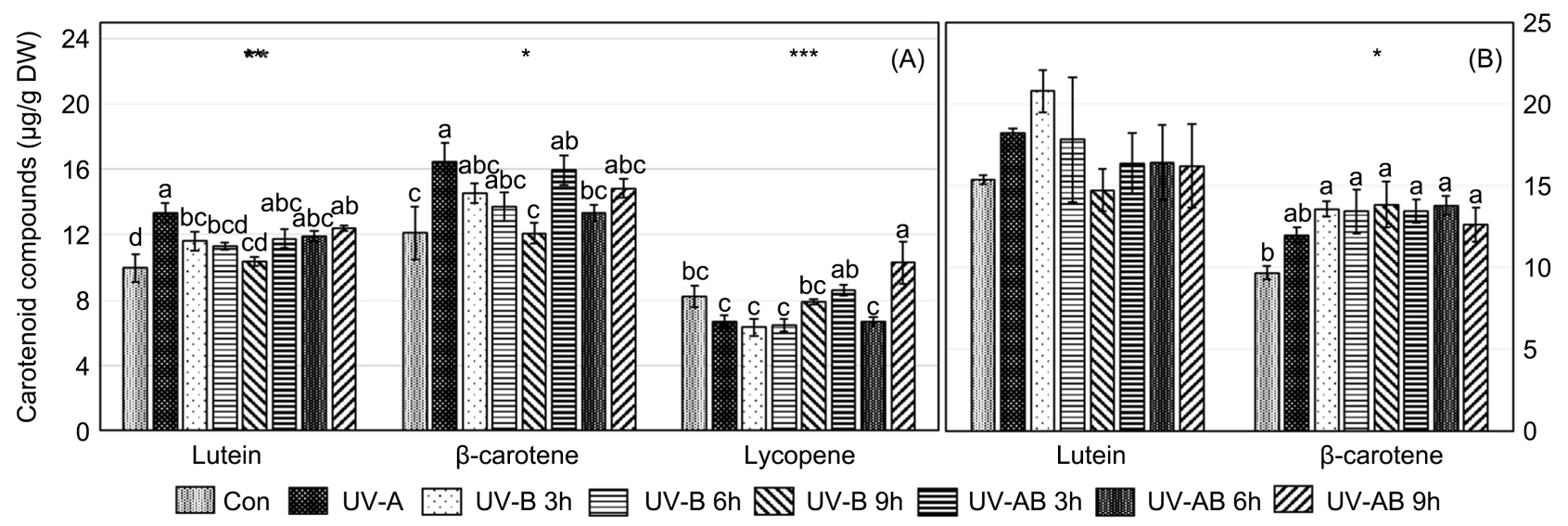

Figure 9. Individual carotenoids compounds in tomato fruits. Plants were treated with supplemental UV-A, and UV-B and $\mathrm{UV}-\mathrm{AB}$ for $3 \mathrm{~h}$ and $6 \mathrm{~h}$. Control plants (con) did not receive any UV treatment. Carotenoid compounds included lutein, $\beta$-carotene, and lycopene from fully ripe (A) and breaker (B) fruits. Bars (SE) with the same letter(s) show no significant treatment differences. Significant differences are indicated by ${ }^{* *}$ and ${ }^{* * *}$ at $\mathrm{p}<0.01$ and $\mathrm{p}<0.001$, respectively. NS indicates lack of significant differences. 
Table 6. Concentrations of essential nutrients in tomato fruits from plants subjected to supplemental UV radiation.

\begin{tabular}{|c|c|c|c|c|c|c|c|c|c|c|c|c|}
\hline & Light source & $\begin{array}{c}\text { Protein } \\
(\%)\end{array}$ & C (\%) & $\mathrm{P}(\%)$ & K (\%) & $\mathrm{Ca}(\%)$ & $\operatorname{Mg}(\%)$ & SO4-S (\%) & $\begin{array}{c}\mathrm{Cu} \\
(\mathrm{ppm})\end{array}$ & $\begin{array}{c}\mathrm{Fe} \\
(\mathrm{ppm})\end{array}$ & $\begin{array}{c}\mathrm{Mn} \\
(\mathrm{ppm})\end{array}$ & $\begin{array}{c}\mathrm{Zn} \\
(\mathrm{ppm})\end{array}$ \\
\hline \multirow{9}{*}{$\begin{array}{l}\text { Red tomato } \\
\text { fruits }\end{array}$} & Control & 8.3 & 38.7 & $0.319 \mathrm{ab}$ & 3.16 & 0.08 & 0.133 & 0.117 & 2.7 & 31.7 & 9.5 & 13.53 \\
\hline & UV-A & 8.2 & 38.53 & $0.328 \mathrm{ab}$ & 3.2 & 0.09 & 0.146 & 0.112 & 2.4 & 27.3 & 8.4 & 13.1 \\
\hline & UV-B $3 \mathrm{~h}$ & 8.5 & 38.17 & $0.354 \mathrm{a}$ & 3.36 & 0.08 & 0.156 & 0.125 & 2.4 & 27.2 & 9.1 & 14.73 \\
\hline & UV-B $6 \mathrm{~h}$ & 7.8 & 37.27 & $0.343 \mathrm{a}$ & 3.31 & 0.1 & 0.15 & 0.122 & 2.1 & 26.8 & 9.8 & 12.97 \\
\hline & UV-B $9 \mathrm{~h}$ & 8.4 & 38.33 & $0.349 \mathrm{a}$ & 3.26 & 0.067 & 0.146 & 0.105 & 2.8 & 29 & 8.4 & 12.37 \\
\hline & UV-AB $3 \mathrm{~h}$ & 8.3 & 37.81 & $0.304 \mathrm{~b}$ & 3.06 & 0.08 & 0.138 & 0.105 & 2.6 & 28.9 & 7.4 & 11.97 \\
\hline & UV-AB $6 \mathrm{~h}$ & 8 & 38.21 & $0.322 \mathrm{ab}$ & 3.22 & 0.08 & 0.145 & 0.111 & 2.6 & 24.9 & 7.1 & 13.97 \\
\hline & UV-AB $9 \mathrm{~h}$ & 8 & 37.88 & $0.349 \mathrm{a}$ & 3.22 & 0.09 & 0.144 & 0.116 & 1.9 & 28.1 & 8.7 & 13.03 \\
\hline & Significance & NS & NS & * & NS & NS & NS & NS & NS & NS & NS & NS \\
\hline \multirow{9}{*}{$\begin{array}{l}\text { Breaker } \\
\text { tomato } \\
\text { fruits }\end{array}$} & Control & 7.58 & 38.98 & 0.31 & 3.21 & 0.078 & 0.153 & 0.1 & 2.35 & 34.9 & 10.1 & 15.95 \\
\hline & UV-A & 8.67 & 38.42 & 0.32 & 3.07 & 0.091 & 0.168 & 0.105 & 2.45 & 31.6 & 11.2 & 13.98 \\
\hline & UV-B $3 \mathrm{~h}$ & 8.48 & 38.48 & 0.34 & 3.4 & 0.088 & 0.174 & 0.106 & 2.2 & 25.6 & 10.1 & 11.33 \\
\hline & UV-B $6 \mathrm{~h}$ & 9.63 & 38.47 & 0.35 & 3.25 & 0.092 & 0.177 & 0.108 & 1.77 & 27.1 & 11.8 & 12.4 \\
\hline & UV-B 9 h & 8.69 & 38.48 & 0.31 & 2.92 & 0.089 & 0.146 & 0.1 & 1.5 & 13.5 & 10.4 & 9.47 \\
\hline & UV-AB $3 \mathrm{~h}$ & 8.5 & 38.81 & 0.28 & 2.92 & 0.091 & 0.144 & 0.098 & 1.77 & 15.4 & 11.4 & 9.73 \\
\hline & $\mathrm{UV}-\mathrm{AB} 6 \mathrm{~h}$ & 8.67 & 38.42 & 0.31 & 3.2 & 0.104 & 0.166 & 0.107 & 1.77 & 22.4 & 9.3 & 12.33 \\
\hline & UV-AB $9 \mathrm{~h}$ & 8.77 & 38.78 & 0.32 & 3 & 0.1 & 0.162 & 0.11 & 2.23 & 19.2 & 11.8 & 12.53 \\
\hline & Significance & NS & NS & NS & NS & NS & NS & NS & NS & NS & NS & NS \\
\hline
\end{tabular}

Significant differences are indicated by ${ }^{*}$ at $\mathrm{p}<0.05(\mathrm{n}=4)$. NS indicates lack of significant differences. Means followed by same letter(s) in a column are not significantly different. Protein concentration was derived from the total leaf nitrogen.

\section{Summary}

In summary, the response of red and green leaf lettuce varieties to supplemental UV-A was variable and was dependent on the variety. Supplemental UV-A enhanced the accumulation of many phenolic compounds such as chlorogenic acid, luteolin-7-glu, quercetin-3-glu, and apigenin-3-gluc in red leaf lettuce. However, UV-B and UV-AB increased the accumulation of many essential nutrients including protein, phosphorus, potassium, calcium, sulfur, and zinc in green leaf lettuce. Similarly, supplemental UV-AB played an important role in enhancing the accumulation of a number of phenolic compounds such as chlorogenic acid, caffeic acid, chicoric acid, luteolin-7-glu, apigenin-3-glu, and kaempferol-3-glu in fully ripe tomato fruits. In addition, supplemental UV treatment resulted in higher accumulation of carotenoids including lutein, $\beta$-carotene, and lycopene in fully ripe fruits. Thus, the results show that supplemental UV radiation can 
enhance the nutritional quality of lettuce and tomato by increasing the accumulation of both health-promoting phenolic compounds and carotenoids.

\section{Conflicts of Interest}

The authors declare no conflicts of interest regarding the publication of this paper.

\section{References}

[1] Krizek, D.T. (2004) Influence of PAR and UV-A in Determining Plant Sensitivity and Photomorphogenic Responses to UV-B Radiation. Photochemistry and Photobiology, 79, 307-315. https://doi.org/10.1111/j.1751-1097.2004.tb00013.x

[2] Verdaguer, S., Jansen, M.A.K., Llorens, L. and Morales, L.O. (2017) UV-A Radiation Effects on Higher Plants: Exploring the Known unknown. Plant Science, 255, 72-81. https://doi.org/10.1016/j.plantsci.2016.11.014

[3] Teramura, A.H. (1983) Effect of Ultraviolet-B Radiation on the Growth and Yield of Crop Plants. Physiologia Plantarum, 58, 415-427. https://doi.org/10.1111/j.1399-3054.1983.tb04203.x

[4] Rozema, J., Staaji, J., Bjorn, L. and Caldwell, M. (1997) UV-B as an Environmental Factor in Plant Life: Stress and Regulation. Trends in Ecology and Evolution, 12, 22-28. https://doi.org/10.1016/S0169-5347(96)10062-8

[5] Tsormpatsidis, E., Henbest, R.G.C., Davis, F.J., Battey, N.H., Hadley, P. and Wagstaffe, A. (2008) UV Irradiance as a Major Influence on Growth, Development and Secondary Products of Commercial Importance in Lollo Rosso Lettuce 'Revolution' Grown under Polyethylene Films. Environmental Experimental Botany, 63, 232-239. https://doi.org/10.1016/j.envexpbot.2007.12.002

[6] Huché-Thélier, L., Crespel, L., Gourrierec, J.L., Morel, P., Sakr, S. and Leduc, N. (2016) Light Signaling and Plant Responses to Blue and UV Radiations-Perspectives for Applications in Horticulture. Environmental Experimental Botany, 121, 22-38. https://doi.org/10.1016/j.envexpbot.2015.06.009

[7] Hollósy, F. (2002) Effects of Ultraviolet Radiation on Plant Cells. Micron, 33, 179-197. https://doi.org/10.1016/S0968-4328(01)00011-7

[8] Frohnmeyer, H. and Staiger, D. (2003) Ultraviolet-B Radiation-Mediated Responses in Plants. Balancing Damage and Protection. Plant Physiology, 133, 1420-1428. https://doi.org/10.1104/pp.103.030049

[9] Braun, J. and Tevini, M. (1993) Regulation of UV-Protective Pigment Synthesis in the Epidermal Layer of Rye Seedlings (Secale cereal L. cv. Kustro). Photochemistry Photobiology, 57, 318-323. https://doi.org/10.1111/j.1751-1097.1993.tb02294.x

[10] Prior, R.L. and Cao, G. (2000) Antioxidant Phytochemicals in Fruits and Vegetables: Diet and Health Implications. HortScience, 35, 588-592.

https://doi.org/10.21273/HORTSCI.35.4.588

[11] Birt, D.F., Hendrich, S. and Wang, W. (2001) Dietary Agents in Cancer Prevention: Flavonoids and Isoflavonoids. Pharmacology \& Therapeutics, 90, 157-177. https://doi.org/10.1016/S0163-7258(01)00137-1

[12] Zhao, X., Iwamoto, T. and Carey, E.E. (2007) Antioxidant Capacity of Leafy Vegetables as Affected by High Tunnel Environment, Fertilisation and Growth Stage. Journal of the Science of Food and Agriculture, 87, 2692-2699. https://doi.org/10.1002/jsfa.3032 
[13] Oh, M.M., Carey, E.E. and Rajashekar, C.B. (2011) Antioxidant Phytochemicals in Lettuce Grown in High Tunnels and Open Field. Horticulture, Environment, and Biotechnology, 52, Article No. 133. https://doi.org/10.1007/s13580-011-0200-y

[14] Müller, O. and Krawinkel, M. (2005) Malnutrition and Health in Developing Countries. Canadian Medical Association Journal, 173, 279-286. https://doi.org/10.1503/cmaj.050342

[15] Linus Pauling Institute (2018) Micronutrient Inadequacies in the U.S. Population: An Overview. Oregon State University. https://lpi.oregonstate.edu/mic/micronutrient-inadequacies/overview

[16] Wu, G., Bazer, F.W. and Cross, H.R. (2014) Land-Based Production of Animal Protein: Impacts, Efficiency, and Sustainability. Annals of the New York Academy of Sciences, 1328, 18-28.

[17] Tulchinsky, T.H. (2010) Micronutrient Deficiency Conditions: Global Health Issues. Public Health Reviews, 32, 243-255. https://doi.org/10.1007/BF03391600

[18] Ritchie, H. and Roser, M. (2017) Micronutrient Deficiency. https://ourworldindata.org/micronutrient-deficiency

[19] Porra, R.J., Thompson, W.A. and Kriedemann, P.E. (1989) Determination of Accurate Extinction Coefficients and Simultaneous Equations for Assaying Chlorophylls A and B Extracted with Four Different Solvents: Verification of the Concentration of Chlorophyll Standards by Atomic Absorption Spectroscopy. Biochimica et Biophysica Acta-Bioenergetics, 975, 384-394. https://doi.org/10.1016/S0005-2728(89)80347-0

[20] Chen, X.I., Wang, L.C., Li, T., Yang, Q.C. and Guo W.Z. (2019) Sugar Accumulation and Growth of Lettuce Exposed to Different Lighting Modes of Red and Blue LED Light. Scientific Reports, 9, Article No. 6926. https://doi.org/10.1038/s41598-019-43498-8

[21] Nakata, M., Mitsuda, N., Herde, M., Koo, A.J., Moreno, J.E., Suzuki, K., Howe, G.A. and Ohme-Takagi, M. (2013) A bHLH-Type Transcription Factor, ABA-Inducible bHLH-Type Transcription Factor/JA-Associated MYC2-LIKE1, Acts as a Repressor to Negatively Regulate Jasmonate Signaling in Arabidopsis. The Plant Cell, 25, 1641-1656. https://doi.org/10.1105/tpc.113.111112

[22] Ainsworth, E.A. and Gillespie, K.M. (2007) Estimation of Total Phenolic Content and Other Oxidation Substrates in Plant Tissues Using Folin-Ciocalteu Reagent. Nature Protocols, 2, 875-877. https://doi.org/10.1038/nprot.2007.102

[23] Miller, N.J. and Rice-Evans, C.A. (1996) Spectrophotometric Determination of Antioxidant Activity. Redox Report, 2, 161-171. https://doi.org/10.1080/13510002.1996.11747044

[24] Pennycooke, J.C., Cox, S. and Stushnoff, C. (2005) Relationship of Cold Acclimation, Total Phenolic Content and Antioxidant Capacity with Chilling Tolerance in Petunia (Petunia x Hybrida). Environmental and Experimental Botany, 53, 225-232. https://doi.org/10.1016/j.envexpbot.2004.04.002

[25] Milton, K. and Dintzis, F.R. (1981) Nitrogen-to-Protein Conversion Factors for Tropical Plant Samples. Biotropica, 13, 177-181. https://doi.org/10.2307/2388122

[26] Krizek, D.T., Britz, S.J. and Mirecki, R.M. (1998) Inhibitory Effects of Ambient Levels of Solar UV-A and UV-B Radiation on Growth of CV. New Red Fire Lettuce. Physiologia Plantarum, 103, 1-7. https://doi.org/10.1034/j.1399-3054.1998.1030101.x

[27] Mark, U. and Tevini, M. (1997) Effects of Solar Ultraviolet-B Radiation, Tempera- 
ture and $\mathrm{CO}_{2}$ on Growth and Physiology of Sunflower and Maize Seedlings. Plant Ecology, 128, 224-234. https://doi.org/10.1023/A:1009798528605

[28] Singh, S.K., Reddy, K.R., Reddy, V.R. and Gao, W. (2014) Maize Growth and Developmental Responses to Temperature and Ultraviolet-B Radiation Interaction. Photosynthetica, 52, 262-271. https://doi.org/10.1007/s11099-014-0029-6

[29] Caldwell, M.M., Flint, S.D. and Searles, P.S. (1994) Spectral Balance and UV-B Sensitivity of Soybean: A Field Experiment. Plant, Cell \& Environment, 17, 267-276. https://doi.org/10.1111/j.1365-3040.1994.tb00292.x

[30] Li, Q. and Kubota, C. (2009) Effects of Supplemental Light Quality on Growth and Phytochemicals of Baby Leaf Lettuce. Environmental Experimental Botany, 67, 59-64. https://doi.org/10.1016/j.envexpbot.2009.06.011

[31] Yao, Y., Yang, Y., Ren, J. and Li, C. (2006) UV-Spectra Dependence of Seedling Injury and Photosynthetic Pigment Change in Cucumis sativus and Glycine max. Environmental Experimental Botany, 57, 160-167. https://doi.org/10.1016/j.envexpbot.2005.05.009

[32] Lee, M.J., Son, J.E. and Oh, M.M. (2013) Growth and Phenolic Compounds of Lactuca sativa L. Grown in a Closed-Type Plant Production System with UV-A, -B, or -C Lamp: Growth and Compounds of Lactuca sativa L. Journal of the Science of Food and Agriculture, 94, 197-204. https://doi.org/10.1002/jsfa.6227

[33] Jeon, Y.M., Son, K.H., Kim, S.M. and Oh, M.M. (2018) Growth of Dropwort Plants and Their Accumulation of Bioactive Compounds after Exposure to UV Lamp or LED Irradiation. Horticulture, Environment, and Biotechnology, 59, 659-670. https://doi.org/10.1007/s13580-018-0076-1

[34] LaFemina, R.L., Schneider, C.L., Robbins, H.L., Callahan, P.L., LeGrow, K., Roth, E., Schleif, W.A. and Emini, E.A. (1992) Requirement of Active Human Immunodeficiency Virus Type 1 Integrase Enzyme for Productive Infection of Human T-Lymphoid Cells. Journal of Virology, 66, 7414-7419. https://doi.org/10.1128/JVI.66.12.7414-7419.1992

[35] Schmitz-Hoerner, R. and Weissenbock, G. (2003) Contribution of Phenolic Compounds to the UV-B Screening Capacity of Developing Barley Primary Leaves in Relations to DNA Damage and Repair under Elevated UV-B Levels. Phytochemistry, 64, 243-255. https://doi.org/10.1016/S0031-9422(03)00203-6

[36] Morales, L.O., Tegelberg, R., Brosche, M., Keinanen, M., Lindfors, A. and Aphalo, P.J. (2010) Effects of Solar UV-A and UV-B Radiation on Gene Expression and Phenolic Accumulation in Betula pendula Leaves. Tree Physiology, 30, 923-934. https://doi.org/10.1093/treephys/tpq051

[37] Gerber, P.J., Steinfeld, H., Henderson, B., Motte, A., Opio, C., Dijkman, J., Falcucci, A. and Tempio, G. (2013) Tackling Climate Change through Livestock: A Global Assessment of Emissions and Mitigation Opportunities. Food and Agriculture Organization, Rome, $139 \mathrm{p}$.

[38] De-Onis, M., Monteiro, C., Akré, J. and Clugston, G. (1993) The Worldwide Magnitude of Protein-Energy Malnutrition: An Overview from the WHO Global Database on Child Growth. Bulletin of World Health Organization, 71, 703-712.

[39] Giuntini, D., Graziani, G., Lercari, B., Fogliano, V., Soldatini, G.F. and Ranieri, A. (2005) Changes in Carotenoid and Ascorbic Acid Contents in Fruits of Different Tomato Genotypes Related to the Depletion of UV-B Radiation. Journal of Agricultural and Food Chemistry, 53, 3174-3181. https://doi.org/10.1021/jf0401726

[40] Živanović, B., Vidović, M., MilićKomić, S., Jovanović, L., Kolarž, P., Morina, F. and Veljović Jovanović, S. (2017) Contents of Phenolics and Carotenoids in Tomato 
Grown under Polytunnels with Different UV-Transmission Rates. Turkish Journal of Agriculture and Forestry, 41, 113-120. https://doi.org/10.3906/tar-1612-56

[41] Giovannucci, E., Rimm, E.B., Liu, Y., Stampfer, M.J. and Willett, W.C. (2002) A Prospective Study of Tomato Products, Lycopene, and Prostate Cancer Risk. Journal of National Cancer Institute, 94, 391-398. https://doi.org/10.1093/jnci/94.5.391

[42] Abdel-Aal, E.S., Akhtar, H., Zaheer, K. and Ali, R. (2013) Dietary Sources of Lutein and Zeaxanthin Carotenoids and Their Role in Eye. Nutrients, 5, 1169-1185. https://doi.org/10.3390/nu5041169 